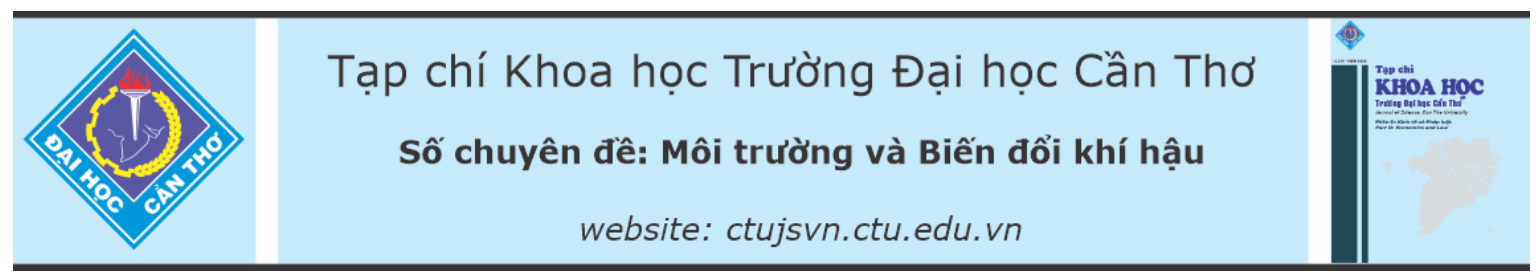

DOI:10.22144/ctu.jsi.2021.047

\title{
BỔ SUNG THAN SINH HỌC TRẤU VÀ TRE LÀM GIẢM PHÁT THẢI KHÍ CH CỦA ĐÂTT NGậP NƯỚC TRONG ĐIỀU KIỆN PHÒNG THÍ NGHIỆM
}

\author{
Trần Sỹ Nam ${ }^{1 *}$, Hồ Vũ Khanh ${ }^{2}$, Hồ Minh Nhựt ${ }^{1}$ và Nguyễn Hữu Chiếm ${ }^{1}$ \\ ${ }^{1}$ Khoa Môi truờng và Tài nguyên Thiên nhiên, Truờng Đại học Cần Tho \\ ${ }^{2}$ Khoa Tài nguyên - Môi truờng, Truờng Đại học Kiên Giang \\ *Người chịu trách nhiệm về bài viết: Trần Sỹ Nam (email: tsnam@ctu.edu.vn)
}

\section{Thông tin chung:}

Ngày nhận bài: $12 / 04 / 2021$

Ngày nhận bài sủa: 18/08/2021

Ngày duyệt đăng: 15/11/2021

\section{Title:}

Rice husk and bamboo biochar amendment in flooded soil reduce methane emission - a lab scale experiment

\section{Tù khóa:}

Đất ngập, điều kiện phòng thi nghiệm, than trấu, than tre, phát thải $\mathrm{CH}_{4}$

\section{Keywords:}

Bamboo biochar, $\mathrm{CH}_{4}$ emission, flooded soil, laboratory conditon, rice husk biochar

\begin{abstract}
Biochar amendment is considered as a method improving and reducing $\mathrm{CH}_{4}$ emission from paddy fields. The study was conducted to evaluate the reduction of $\mathrm{CH}_{4}$ emission when supplement of different biochar into flooded soil in the laboratory condition. The study was a completely randomized design with 7 treatments including rice husk biochar (RB) and bamboo biochar $(B B)$ at 3 ratios of supplemented biochar at 0.1, 0.2 and $0.5 \%$ (calculated by weight of biochar and weight of soil) and the control (without biochar). The results showed that $\mathrm{CH}_{4}$ emission rates were highest, at 58.2-87.9 $\mu \mathrm{g} / \mathrm{kg} /$ day, during 7-10 days after incubation. Adding rice husk biochar into flooded soil reduces $\mathrm{CH}_{4}$ emissions from $21.9-49.6 \%$ and $27.5-42.5 \%$ when added $0.2-0.5 \%$ of rice husk and bamboo biochar, respectively. Amending of rice husk biochar at $0.5 \%$ resulted in reducing of $49.64 \%$ of total methane emission compared to the control. It is necessary to conduct the field experiment to confirm the reducion of methane emission when applying biochar in the paddy fields.
\end{abstract} TÓM TÁ̀T

Bổ sung than sinh học vào đất được xem là một biện pháp trong cải tạo đất và giảm phát thải khí $\mathrm{CH}_{4}$ tù̀ ruộng lúa. Nghiên cúu được thưc hiện nhằm đánh giá hiệu quả giảm phát thải khi methane $\left(\mathrm{CH}_{4}\right)$ của đất ngập nuớc khi bổ sung than sinh học trấu (RB) và tre $(B B)$ trong điều kiện phòng thi nghiệm. Thí nghiệm được bố trí hoàn toàn ngẫu nhiên với 7 nghiệm thức gồm hai loại than sinh học là trấu và tre với 3 tỷ lệ than sinh hoc được bô sung là 0,1, 0,2 và 0,5\% (tính theo trong luợng than sinh hoc trên trọng luợng đất) và nghiệm thức đối chứng (không có than sinh học). Kết quả đo đạc cho thấy trong điều kiện đất ngập nước, cường độ phát thải khi $\mathrm{CH}_{4}$ mạnh nhất tù̀ 7-10 ngày sau khi bằt đầu thí nghiệm (với mưcc

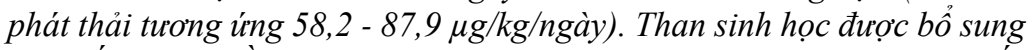
vào đất trong điều kiện ngập nước làm giảm phát thải $\mathrm{CH}_{4}$ tù̀ 21,9 đến $49,6 \%$ và 27,5 - 42,5\% tuoong ứng với tỷ lệ bồ sung than tù 0,2 đến $0,5 \%$ (lần luợt cho than trấu và than tre). Than sinh học trấu bổ sung ở tỷ lệ 0,5\% có mức giảm 49,64\% tổng phát thải khi $\mathrm{CH}_{4}$ so với nghiệm thức đối chưng. Nghiên cứu cần thực hiện trong điều kiện đồng ruộng để đánh giá tác động của việc bổ sung than trong điều kiện thực tế. 


\section{1. ĐĂT VẤN ĐỀ}

Đất lúa là nguồn phát khí nhà kính (GHGs) nhiều nhất trong nông nghiệp (Smith et al., 2017). Tổng lượng phát thải khí nhà kính (GHE) của Việt Nam ước tính là 37,43 triệu tấn, $58 \% \mathrm{CH}_{4}$ phát thải từ các hoạt động nông nghiệp, xếp thứ 11 trên thế giới (MONRE, 2010). $\mathrm{CH}_{4}$ được xem là khí phát thải nhiều nhất trên đồng ruộng. Vì vậy, giảm phát thải $\mathrm{CH}_{4}$ cũng như tăng cường khả năng và lượng cô lập carbon trong hệ sinh thái đất đóng vai trò quan trọng trong việc ứng phó với biến đổi khí hậu (Cheng et al., 2016). Trong đất trồng lúa, $\mathrm{CH}_{4}$ là sản phẩm cuối cùng của quá trình phân hủy các vật chất hữu cơ bởi vi sinh vật (VSV) trong điều kiện yếm khí, và một phần khí $\mathrm{CH}_{4}$ tạo ra sẽ bị oxy hóa bởi các VSV methanotrophs trong lớp đất mặt xung quanh rễ cây, phần còn lại phát thải vào khí quyển chủ yếu bằng con đường khuếch tán qua hệ thống mạch thông khí (Conrad et al., 2006). Nhiều nghiên cứu cho thấy lượng $\mathrm{CH}_{4}$ phát thải thường phụ thuộc vào tính chất vật lý và hóa học của than sinh học (biochar), loại đất, điều kiện môi trường sống của VSV, kỹ thuật làm đất, quản lý nước và phân bón, gieo trồng hay khí hậu (Inubushi, 1989 trích dẫn bởi Phạm Quang Hà và ctv., 2013; Xiong et al., 2007; Zwieten et al., 2009;).

Biochar được tạo thành từ quá trình nhiệt phân ở nhiệt độ cao nên khó bị phân hủy, có diện tích bề mặt lớn với nhiều lỗ rô̂ng, có khả năng hấp phụ mạnh và là môi trường sống cho nhiều loài VSV trong đất, nên có nhiều ý nghĩa trong lưu giữ carbon và cải thiện tính chất đất (Lehmann \& Joseph, 2009; Liang et al., 2006). Gần đây, nhiệt phân gỗ và một số phụ phẩm nông nghiệp để sản xuất biochar được xem là các biện pháp để hạn chế ô nhiễm môi trường và giảm phát thải khí nhà kính hiệu quả (Mai Văn Trịnh và ctv., 2013). Biochar có khả năng làm giảm phát thải khí $\mathrm{CH}_{4}$, nghiên cứu của Spokas and Reicosky (2009) và Karhu et al. (2011) cho thấy bổ sung biochar ở tỷ lệ 2-60\% sẽ làm giảm phát thải $\mathrm{CH}_{4}$ tối đa lên đến $91,2 \%$ so với không bố sung biochar vào đất. Theo Liu et al. (2011), trong điều kiện phòng thí nghiệm (không trồng lúa), khi bổ sung biochar tre ở mức $1,5-2 \%$ giảm $51,1 \%$ và biochar rơm rạ làm giảm $91,2 \%$ lượng $\mathrm{CH}_{4}$ sinh ra từ đất. Đồng bằng sông Cửu Long (ĐBSCL) là vùng có nguồn nguyên liệu dồi dào trong việc sản xuất than sinh học từ trấu để giảm phát thải khí nhà kính. Sản lượng lúa hằng năm là 24,5 triệu tấn (Tổng cục thống kê, 2016) và lượng trấu sinh ra bằng $20 \%$ lượng lúa sau xay xát gạo (Chungsangusist et al., 2009). Theo Bộ Nông nghiệp và Phát triển Nông thôn (2017), cả nước có diện tích rừng tre luồng lớn với 73.293 ha, tre tăng trưởng nhanh từ 10-30\% sinh khối mỗi năm, tre có thể được thu hoạch có chọn lọc và tái sinh một cách tự nhiên mà không cần trồng lại. Đây là hai nguồn nguyên liệu dồi dào ở ĐBSCL có thể dùng để sản xuất biochar, vì nó có tính hấp phụ tốt và sản xuất với số lượng lớn để bổ sung cho đất làm giảm phát thải khí $\mathrm{CH}_{4}$ và cải thiện môi trường đất.

Việt Nam có diện tích đất nông nghiệp trồng lúa chiếm tỷ lệ lớn, với tổng diện tích gieo sạ năm 2017 là 7,72 triệu ha, riêng ĐBSCL có diện tích gieo trồng biến động theo từng vụ từ 769,4 nghìn ha đến 3 triệu ha (Tổng cục thống kê, 2018). Bên cạnh hoạt động sản xuất lúa rất đa dạng về kiểu luân canh và chế độ canh tác, kỹ thuật gieo trồng, quản lý nước và phân bón trên các loại đất khác nhau. Đặc biệt, ở ĐBSCL thâm canh tăng vụ, bón phân hóa học, để nước ngập liên tục trong canh tác đang diễn ra phổ biến (Huỳnh Quang Tín và ctv., 2015; Tô Lan Phương và ctv., 2012). Việc thâm canh và tăng vụ làm cho ruộng lúa luôn trong tình trạng ngập nước liên tục, môi trường đất ở tình trạng hiếm khí, thuận lợi cho sự phân hủy chất hữu cơ và phát thải $\mathrm{CH}_{4}$, sự phát thải từ sự sủi bọt khí trong đất ngập nước kể cả khi không có cây trồng chiếm 49-64\% (Barlett et al., 1988). Vì vậy, nghiên cứu được thực hiện nhằm sử dụng than trấu và than tre để giảm phát thải $\mathrm{CH}_{4}$ của đất ngập nước từ quá trình phân hủy hữu cơ tự nhiên trong đất ở điều kiện phòng thí nghiệm.

\section{VÂT LIÊU VÀ PHƯƠNG PHÁP NGHIỀ CÚU}

\subsection{Vật liệu thí nghiệm}

\subsection{1. Đất}

Đất được thu tầng 0-10 cm, trên ruộng lúa tại phường Thới An Đông, quận Bình Thủy, thành phố Cần Thơ $\left(10^{\circ} 04^{\prime} 26,6^{\prime \prime} \mathrm{N} ; 105^{\circ} 40^{\prime} 59,5^{\prime}\right.$ ”E). Đất sử dụng trong thí nghiệm thuộc loại đất phù sa có tính phèn nhẹ theo hệ thống phân loại WRB-FAO (2006) đây là loại đất có diện tích lớn nhất ở ĐBSCL, với hơn 1,91 triệu ha (Võ Quang Minh \& Phan Thanh Vũ, 2015).

Đất sau khi thu về từ ruộng được trộn đều, phơi khô (ở nhiệt độ phòng) và nghiền qua rây $2 \mathrm{~mm}$ để phân tích $\mathrm{pH}, \mathrm{EC}$ (trích theo tỷ lệ 1:5), tổng đạm (TN) xác định theo Kjeldahl, chất hữu cơ $(\mathrm{CHC})$ xác định theo phương pháp Walkley-Black. Mẫu dung trọng sau khi được thu ngoài đồng bằng ring với thể tích $100 \mathrm{~cm}^{3}$ được xác định theo tài liệu hướng dẫn của Ngô Ngọc Hưng (2004). 


\subsubsection{Biochar}

Nghiên cứu sử dụng biochar được tạo từ 2 loại nguyên liệu là vỏ trấu và thân tre tương tự nghiên cứu của Nguyễn Khoa Nam và ctv. (2018):

- Biochar trấu: Nguyên liệu vỏ trấu được thu tại nhà máy xay xát rồi sử dụng lò hầm than do Trường Đại học Kỹ thuật nông nghiệp Tokyo (TUAT) - Nhật chế tạo để tạo than trấu. Vỏ trấu được hầm trong điều kiện bán yếm khí liên tục trong 3 giờ, nhiệt độ hầm dao động từ $400^{\circ} \mathrm{C}$ đến $440^{\circ} \mathrm{C}$ trong quá trình than hóa (Hình 1a).

- Biochar tre: Tre sử dụng để hầm than trong thí nghiệm thuộc loại Tre gai (Bambusa bambos (L.) Voss), thân tre được cắt thành đoạn dài $30-40 \mathrm{~cm}$,

sau đó được đưa vào lò hầm than truyền thống của người dân địa phương ở huyện Châu Thành, tỉnh Hậu Giang. Lò hầm than được bịt kín để quá trình tạo than xảy ra trong điều kiện bán yếm khí. Nhiệt độ hầm trong lò dao động từ $350^{\circ} \mathrm{C}$ đến $420^{\circ} \mathrm{C}$, quá trình tạo than được thực hiện trong 32 ngày gồm quá trình đốt, than hóa và làm nguội (Hình $1 \mathrm{~b}$ ).

Hai loại biochar sau khi nhiệt phân sẽ được phân tích pH, EC được ly trích 1:10 (Wang et al., 2017), ẩm độ được nung ở $105^{\circ} \mathrm{C}, \% \mathrm{C}$ được nung $550^{\circ} \mathrm{C}$ để xác định, TN xác định theo phương pháp Kjeldahl (Ngô Ngọc Hưng, 2004), chụp độ rỗng (SEM) bằng kính hiển vi điện tử Hitachi TM-1000 (Nhật), một số tính chất lý hóa của than sau khi hầm được ở Bảng 2.
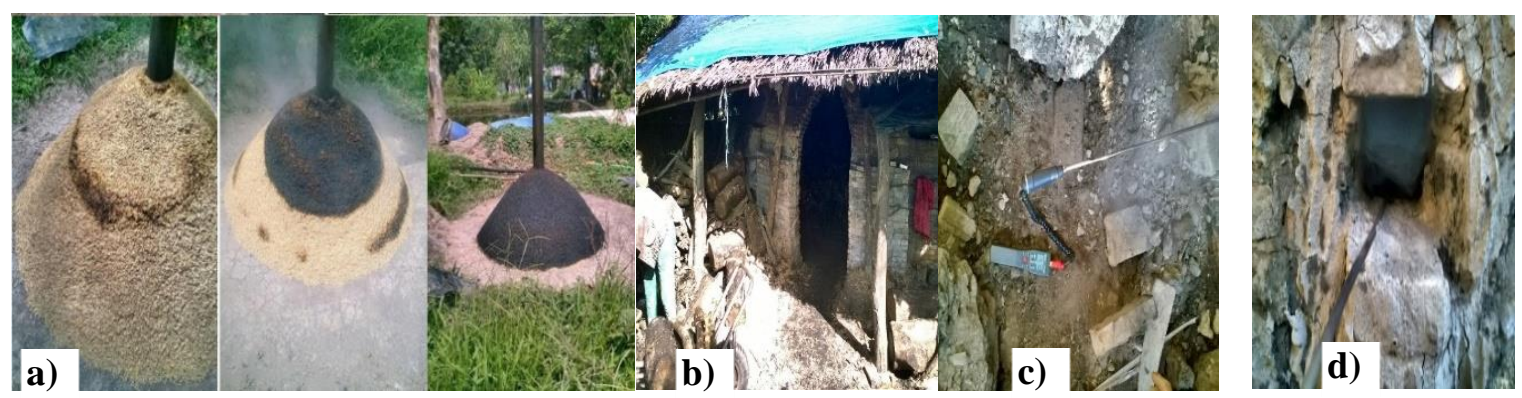

Hình 1: a) Lò hầm than trấu; b) Lò hầm than tre; c) Máy đo nhiệt độ lò hầm than; d) Điểm đặt điện cực đo nhiệt độ lò hầm

\subsection{Bố trí thí nghiệm}

Thí nghiệm được thực hiện trong điều kiện phòng thí nghiệm, tại Khoa Môi trường và Tài nguyên Thiên nhiên, Trường Đại học Cần Thơ. Thí nghiệm được bố trí trong chai thủy tinh $300 \mathrm{~mL}$ (Schott, Đức), thông tin về chai ủ dùng bố trí thí nghiệm được trình bày ở Hình 2 . Thí nghiệm gồm 7 nghiệm thức, được bố trí hoàn toàn ngẫu nhiên với 2 loại than sinh học là trấu và tre, mỗi loại có 3 mức tỷ lệ bổ sung được áp dụng là $0,1 \%, 0,2 \%$ và $0,5 \%$ và đối chứng (không có bổ sung biochar), các nghiệm thức được mô tả chi tiết ở Bảng 1 .

Quy trình bố trí thí nghiệm trong chai ủ được thực hiện như sau:

- Bước 1: Cân lần lượt khối lượng 2 loại biochar là biochar trấu $(\mathrm{RB})$ và biochar tre $(\mathrm{BB})$ của từng nghiệm thức vào các chai thủy tinh (theo trọng lượng mô tả ở Bảng 1).

- Bước 2: Cân $81 \mathrm{~g}$ (tương ứng $100 \mathrm{~cm}^{3}$ đất) đất khô đã nghiền qua rây $2 \mathrm{~mm}$ cho vào chai ủ.
- Bước 3: Thêm $150 \mathrm{~mL}$ nước cất vào mỗi chai thủy tinh, trộn đều để nước ngấm vào hỗn hợp đất, biochar (đảm bảo nước ngập hơn mặt đất $>1 \mathrm{~cm}$ để đảm bảo sự yếm khí của môi trường ủ).

- Bước 4: Đóng chặt các nắp chai thủy tinh và giữ ở nhiệt độ ổn định $30^{\circ} \mathrm{C}$. Đây là khoảng khoảng nhiệt độ thích hợp để methanogenic hoạt động tốt nhất, thuận lợi cho sinh khí $\mathrm{CH}_{4}$ (Inubushi et al., 1990).

Phương pháp thu mẫu khí được thực hiện theo Yoo và Kang (2012) và Troy et al. (2013) với trình tự thực hiện như sau: Các chai thu mẫu được mở thoáng khí 5 phút trước khi thu mẫu, thổi khí nhẹ từ 0,5-1 phút để loại bỏ các khí tích lũy trong chai; đậy kín chai bằng nút cao su, sau đó dùng tiêm kín khí $20 \mathrm{~mL}$ trộn đều không khí bên trong chai. Mẫu khí được thu ở các thời điểm $0,30,60$ phút và chuyển vào lọ kín khí $(14 \mathrm{~mL})$ đã được hút chân không trước đó. Các mẫu khí được phân tích định lượng bằng máy sắc ký khí GC (Shimadzu, Nhật Bản bằng đầu dò FID) để nồng độ khí $\mathrm{CH}_{4}$. 
Bảng 1: Mô tả chi tiết các nghiệm thức

\begin{tabular}{llcc}
\hline Ký hiệu & Nghiệm thức & Trọng lượng đất & Trọng lượng than sinh học \\
\hline NTĐC & Nghiệm thức đối chứng (không bổ sung & $81 \mathrm{~g}$ & $0,00 \mathrm{~g}$ \\
biochar) & Nghiệm thức 0,1\% biochar trấu & $81 \mathrm{~g}$ & $0,081 \mathrm{~g}$ \\
RB1 & Nghiệm thức 0,2\% biochar trấu & $81 \mathrm{~g}$ & $0,162 \mathrm{~g}$ \\
RB2 & Nghiệm thức 0,5\% biochar trấu & $81 \mathrm{~g}$ & $0,405 \mathrm{~g}$ \\
BB1 & Nghiệm thức 0,1\% biochar tre & $81 \mathrm{~g}$ & $0,081 \mathrm{~g}$ \\
BB2 & Nghiệm thức 0,2\% biochar tre & $81 \mathrm{~g}$ & $0,162 \mathrm{~g}$ \\
BB3 & Nghiệm thức 0,5\% biochar tre & & $0,405 \mathrm{~g}$ \\
\hline
\end{tabular}

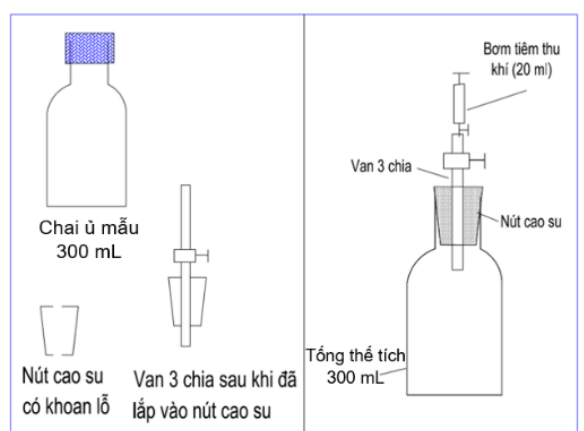

\section{Hình 2: Mô tả chi tiết chai ủ trong thí nghiệm}

\subsection{Tần suất và thời gian thu mẫu}

$\mathrm{CH}_{4}$ phát thải trong thí nghiệm sinh ra từ các chai ủ được theo dõi liên tục trong 3 tuần và với các thời điểm thu mẫu vào các ngày $1,5,7,10,14$ và 21 sau khi bắt đầu thí nghiệm (NSU). Thời gian theo dõi của thí nghiệm được dựa trên một chu kỳ ngập nước dài nhất theo tập quán canh tác của người nông dân (Huỳnh Quang Tín và ctv., 2015; Tô Lan Phương và ctv., 2012), và một số nghiên cứu đánh giá phát thải $\mathrm{CH}_{4}$ ở điều kiện phòng thí nghiệm đã được thực hiện của Liu et al. (2011), Wang et al. (2017) và Yoo and Kang (2012).

\subsection{Phương pháp phân tích và tính toán lượng phát thải}

Nồng độ $\mathrm{CH}_{4}$ trong các mẫu khí được thu vào các thời điểm $0,30,60$ phút, sẽ được đo bằng máy sắc ký khí Shimadzu (GC-2014, Nhật) sử dụng đầu dò FID (Cột 60/80 Carboxen ${ }^{\circledR} 1000$ với $\mathrm{L} \times$ O.D $\times$ I.D: 4,57 m×3,1 mm×2,1 mm), $\mathrm{N}_{2}$ được sử dụng làm khí mang với tốc độ dòng $30 \mathrm{~mL} /$ phút. Mẫu khí trong vial sẽ được hút $3 \mathrm{~mL}$ bơm vào buồng chứa mẫu có Loop $=1 \mathrm{~mL}$.

Tốc độ phát thải $\mathrm{CH}_{4}$ được tính theo công thức Parkin et al. (2003), $\left(\mathrm{mgCH}_{4} / \mathrm{kg} / \mathrm{ngày}\right)$ :

$$
\mathrm{F}_{\mathrm{CH}_{4}}=\frac{\mathrm{dC}}{\mathrm{dt}} \times \frac{\mathrm{MW} \times \mathrm{V} \times 60 \times 24}{\mathrm{~m} \times\left(0.08206 \times\left(273+\mathrm{t}^{\circ} \mathrm{C}\right)\right.}
$$

Trong đó, t: nhiệt độ không khí ủ ( $\left.{ }^{\circ} \mathrm{K}\right)$, MW: trọng lượng phân tử khí $\mathrm{CH}_{4}(\mathrm{~m}=16)$, m: trọng lượng đất sử dụng ủ $(\mathrm{g}), \frac{\mathrm{dc}}{\mathrm{dt}}$ : tốc độ gia tăng nồng độ khí $\mathrm{CH}_{4}(\mathrm{mg} / \mathrm{kg})$; $\mathrm{V}$ : tống thể tích phần khoảng không chứa khí $\mathrm{CH}_{4}$ sinh ra trong chai ủ.

Tổng lượng phát thải $\mathrm{CH}_{4}$ qua các ngày được tính dựa vào công thức của Mai Văn Trịnh và ctv. (2013), (mg/kg) như sau:

$$
\begin{gathered}
\bar{F}=\left(\mathrm{n}_{2}-\mathrm{n}_{1}\right) *\left(\frac{\mathrm{Fn}_{1}+\mathrm{Fn}_{2}}{2}\right)+\left(\mathrm{n}_{3}-\mathrm{n}_{2}\right) *\left(\frac{\mathrm{Fn}_{2}+\mathrm{Fn}_{3}}{2}\right)+\ldots+ \\
\left(\mathrm{n}_{\mathrm{c}}-\mathrm{n}_{\mathrm{x}}{ }^{*}\left(\frac{\mathrm{F}_{\mathrm{nc}}+\mathrm{F}_{\mathrm{nx}}}{2}\right)(2)\right.
\end{gathered}
$$

Trong đó, $\mathrm{n}_{1}, \mathrm{n}_{2}, \mathrm{n}_{3}$ là ngày lấy mẫu thứ $1,2,3$ và $\mathrm{n}_{\mathrm{x}}$ là ngày lấy mẫu thứ $\mathrm{x}, \mathrm{n}_{\mathrm{c}}$ là ngày lấy mẫu cuối cùng và $\mathrm{F}_{\mathrm{n} 1}, \mathrm{~F}_{\mathrm{n} 2}, \mathrm{~F}_{\mathrm{n} 3} \ldots, \mathrm{F}_{\mathrm{n}}$ là lượng phát thải trung bình của khí $\mathrm{CH}_{4}\left(\mathrm{mgCH}_{4} / \mathrm{kg} /\right.$ ngày $)$ ứng với các ngày lấy mẫu $\mathrm{n}_{1}, \mathrm{n}_{2}, \mathrm{n}_{3, \ldots}, \mathrm{n}_{\mathrm{x}}$ và $\mathrm{n}_{\mathrm{c}}$.

\subsection{Xử lý số liệu}

Số liệu được tổng hợp bằng phần mềm Excel 2010. Kiểm tra tính đồng nhất của phương sai trước khi thực hiện thống kê, so sánh tốc độ phát thải khí và tổng lượng khí $\mathrm{CH}_{4}$ của các nghiệm thức được thực hiện theo phương pháp phân tích phương sai ANOVA với phép thử Duncan ở độ tin cậy $95 \%$ bằng phần mềm IBM SPSS 20.0.

\section{KẾT QUẢ VÀ THẢO LUẬN}

\section{1. Đặc điểm lý hóa đất và biochar}

Kết quả Bảng 2 cho thấy đất sử dụng thí nghiệm có dung trọng $0,81 \mathrm{~g} / \mathrm{cm}^{3}$, hàm lượng $\mathrm{C}$ là $4,85 \%$, tương ứng với hàm lượng hữu cơ là $8,36 \%$ thuộc nhóm giàu hữu cơ (Ngô Ngọc Hưng, 2004), hàm lượng tổng đạm là $0,21 \%$ ở mức trung bình, $\mathrm{pH}$ ở mức ít chua 5,85-6,05 và $\mathrm{EC}$ dao động từ $0,25-0,27$ $\mathrm{mS} / \mathrm{cm}$, thích hợp cho sự sinh trưởng và phát triển của cây (Ngô Ngọc Hưng, 2004). Đất thí nghiệm với đặc điểm là có hàm lượng chất hữu cơ cao, kết hợp với thí nghiệm trong điều kiện ngập nước liên tục sẽ là môi trường thuận lợi cho methanogenic phát triển, phân hủy hữu cơ nhanh sinh ra khí $\mathrm{CH}_{4}$ nhiều. Kết quả Bảng 2 cho thấy biochar trấu $(\mathrm{RB})$ có $\mathrm{pH}(9,4)$, EC (1,6 mS/cm), TN (0,45 \%), C/N (135); biochar 
tre có $\mathrm{pH}(8,3), \mathrm{EC}(0,28 \mathrm{mS} / \mathrm{cm}), \mathrm{TN}(0,56 \mathrm{~g} / \mathrm{kg})$, $\mathrm{C} / \mathrm{N}(145)$. Biochar có $\mathrm{pH}, \mathrm{EC}$ cao hơn và $\% \mathrm{C}, \mathrm{N} \%$ tương đương so với nghiên cứu của Huỳnh Phan Khánh Bình và Trương Thị Nga (2019) khi cùng phương pháp nhiệt phân. Kết quả này tương đương khi so với biochar được tạo thành bằng phương pháp nhiệt phân chậm ở $500^{\circ} \mathrm{C}$ của Nguyen et al. (2018) (ngoại trừ $\% \mathrm{C}$ ). Các đặc điểm $\mathrm{pH}, \mathrm{EC}, \mathrm{TN}, \% \mathrm{C}$ hay $\mathrm{C} / \mathrm{N}$ phụ thuộc vào loại nguyên liệu và nhiệt độ nhiệt phân tạo than, và rất khác nhau với từng vật liệu (Lehmann, 2007; Wang et al., 2011). Biochar trấu và tre với ưu điểm diện tích bề mặt lớn, $\mathrm{pH}, \mathrm{EC}, \% \mathrm{C}$ cao là điều kiện phù hợp để cải thiện chất lượng đất như tăng $\mathrm{pH}, \mathrm{EC}, \mathrm{TN}$ kết hợp với nhiều lỗ rỗng trong biochar (Hình 3) là một lợi thế cho sự hấp phụ, tạo điều kiện cư trú cho một số loài VSV nhỏ trong đất (như methanotrops), tránh khỏi các loài cạnh tranh nấm hoặc VSV lớn hơn (Lehmann \& Joseph, 2009; Nguyễn Văn Sinh, 2016;). Điều này có thể góp phần thúc đẩy quá trình giữ lại carbon trong đất, làm giảm sự phát thải khí $\mathrm{CH}_{4}$.

Bảng 2: Đặc tính đất và biochar được sử dụng trong thí nghiệm

\begin{tabular}{lrrr}
\hline Chỉ tiêu & Đất & RB & BB \\
\hline $\mathrm{pH}$ & $5,95 \pm 0,1$ & $9,4 \pm 0,03$ & $8,3 \pm 0,01$ \\
$\mathrm{EC}(\mathrm{mS} / \mathrm{cm})$ & $0,26 \pm 0,1$ & $1,6 \pm 0,03$ & $0,28 \pm 0,1$ \\
$\% \mathrm{C}(\%)$ & $4,85 \pm 0,2$ & $61,0 \pm 3,2$ & $81,2 \pm 1,4$ \\
$\mathrm{TN}(\%)$ & $0,21 \pm 0,02$ & $0,45 \pm 0,01$ & $0,56 \pm 0,03$ \\
$\mathrm{C} / \mathrm{N}$ & $23,2 \pm 1.3$ & $135 \pm 4,1$ & $145 \pm 5,3$ \\
Ầm độ $(\%)$ & - & $6,2 \pm 0,1$ & $6,8 \pm 0,1$ \\
Dung trọng $\left(\mathrm{g} / \mathrm{cm}^{3}\right)$ & $0,81 \pm 0,01$ & - & - \\
\hline
\end{tabular}

$(T B \pm S D, n=3)$

(a) Đất bổ sung than trấu

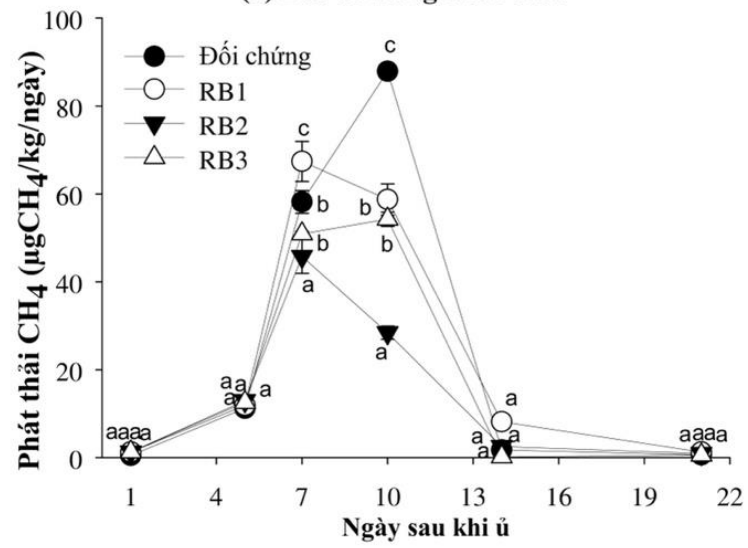

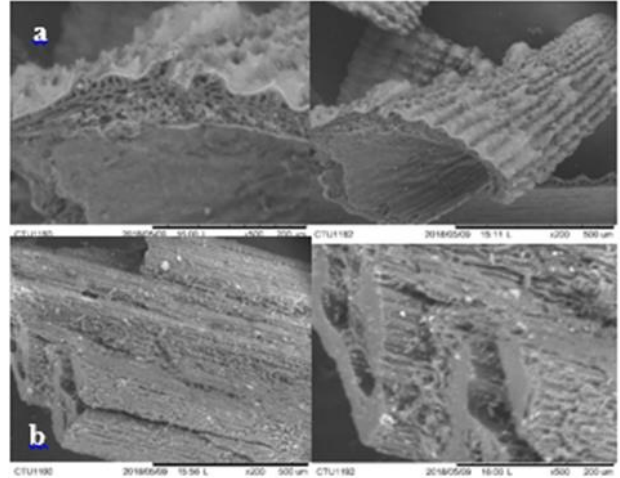

Hình 3: a) Ảnh chụp SEM biochar trấu ở x200 và $x 500 ; b)$ biochar tre $x 200$ và $x 500$ trong thí nghiệm

\section{2. Ảnh hưởng bổ sung biochar trấu và tre đến sự phát thải $\mathrm{CH}_{4}$}

Kết quả Hình 4 cho thấy tốc độ phát thải $\mathrm{CH}_{4}$ của các nghiệm thức bổ sung biochar trấu RB1, RB2, RB3 có giá trị dao động lần lượt là 1,29-67,4, 0,9645,8 và $0,17-54,3 \mu \mathrm{gCH} / \mathrm{kg} /$ ngày. Các nghiệm thức bổ sung than tre $\mathrm{BB} 1, \mathrm{BB} 2$ và $\mathrm{BB} 3$ có tốc độ phát thải khí $\mathrm{CH}_{4}$ ghi nhận lần lượt là $0,48-79,8,0,33$ 79,5 và $0,44-82,1 \mu \mathrm{gCH}_{4} / \mathrm{kg} /$ ngày. Trong khí đó, nghiệm thức đối chứng có $\mathrm{CH}_{4}$ phát thải dao động từ $0,529-87,9 \mu \mathrm{gCH}_{4} / \mathrm{kg} /$ ngày (trung bình 26,7 $\mu \mathrm{gCH}_{4} / \mathrm{kg} /$ ngày), cao vào thời điểm $7 \mathrm{NSU}$ và 10 NSU khác biệt có ý nghĩa thống kê so với các nghiệm thức có bổ sung biochar $(\mathrm{p}<0,05)$, tuy nhiên không có sự khác biệt có ý nghĩa so với các nghiệm thức khác tại các thời điểm còn lại ( $p>0,05)$.

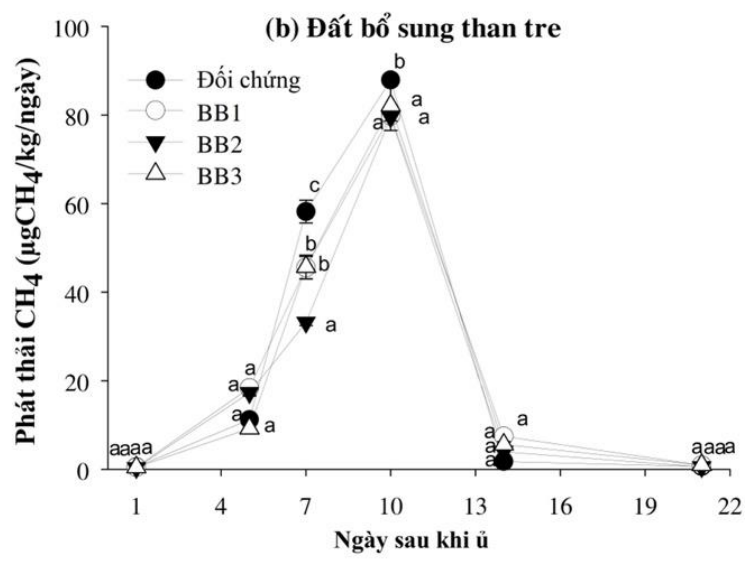

Hình 4: Tốc độ phát thải $\mathrm{CH}_{4}$ hàng ngày trong thời gian thí nghiệm

Ghi chú: Các cột có cùng ít nhất một chũ cái thì không khác biệt ở múc ý nghĩa thống kê 5\%; Đối chứng: nghiệm thức đối chứng, RB1: 0,1\% biochar trấu, RB2: 0,2\% biochar trấu, RB3: 0,5\% biochar trấu, BB1: 0,1\% biochar tre, BB2: $0,2 \%$ biochar tre và $B B 3: 0,5 \%$ biochar tre. 
Xu hướng phát thải khí $\mathrm{CH}_{4}$ trong thí nghiệm được thể hiện ở Hình 4 , có thể chia làm 3 giai đoạn chính: giai đoạn 1: từ 1 đến $5 \mathrm{NSU}$ là giai đoạn hình thành điều kiện thích hợp cho sự sinh khí $\mathrm{CH}_{4}$, giai đoạn 2: từ 6 đến $14 \mathrm{NSU}$ là giai đoạn phát thải $\mathrm{CH}_{4}$ cực đại, giai đoạn 3 : từ 15 đến 21 NSU là giai đoạn $\mathrm{CH}_{4}$ phát thải thấp, dừng phát thải. $\mathrm{CH}_{4}$ phát thải nhanh và nhiều vào thời gian từ 7 đến $10 \mathrm{NSU}$ có thể giải thích do sau khi đất được giữ ngập nước trong 7 ngày, các khí oxy đã bị các VSV hiếu khí và quá trình phân hủy các chất hữu cơ trong đất đã sử dụng hết oxy có sẵn mà sự khuếch tán oxy từ không khí bị hạn chế do qua lớp mặt nước nên môi trường đất chuyển sang trạng thái thiếu oxy (Wang et al., 2017; Yoo and Kang, 2012). Sự thiếu hụt oxy này dẫn đến môi trường yếm khí trong đất, thúc đẩy nhóm VSV yếm khí phân giải hữu cơ sinh $\mathrm{CH}_{4}$ (methanogenic), giảm điện thế oxy hóa khử (Eh <$180 \mathrm{mV})$. Sự phát triển nhanh và mạnh của VSV sinh $\mathrm{CH}_{4}$ đã phân hủy lượng chất hữu cơ có trong đất dẫn đến lượng $\mathrm{CH}_{4}$ được sinh ra nhiều trong thời gian này (Dubey, 2005; Weier et al., 1999). $\mathrm{CH}_{4}$ sinh ra thấp ở ngày 1 đến 5 NSU là do vào giai đoạn đầu thí nghiệm môi trường đất vẫn còn oxy, nên nhóm methanogenic chưa phát triển mạnh (Yoo \& Kang, 2012) để $\sinh \mathrm{CH}_{4}$. Giai đoạn từ 14 đến $21 \mathrm{NSU}$ thì lượng hữu cơ đã giảm, đất thí nghiệm chỉ có lượng hữu cơ nhất định, không có sự bổ sung các nguồn carbon như rơm trong thí nghiệm của Liu et al. (2011), nên thiếu hưu cơ để VSV sinh $\mathrm{CH}_{4}$ tiếp tục quá trình phân hủy hữu cơ sinh $\mathrm{CH}_{4}$, do đó sự phát thải giảm dần và ở mức rất thấp vào $21 \mathrm{NSU}$.

Kết quả Hình 5 cho thấy tổng lượng phát thải khí $\mathrm{CH}_{4}$ sau 21 ngày thí nghiệm của nghiệm thức đối chứng (không được bổ sung biochar) cao nhất $\left(0,556 \mathrm{mgCH}_{4} / \mathrm{kg}\right)$, khác biệt có ý nghĩa với nghiệm thức có bổ sung biochar (trừ nghiệm thức RB1, BB1 với tốc độ phát thải lần lượt là 0,552 và 0,550 $\left.\mathrm{mgCH}_{4} / \mathrm{kg}\right)(\mathrm{p}<0,05)$. Tổng lượng phát thải $\mathrm{CH}_{4}$ của nghiệm thức bổ sung biochar trấu với tỷ lệ $0,2 \%$ $(\mathrm{RB} 2)$ và $0,5 \%(\mathrm{RB} 3)$ có giá trị lần lượt là 0,434 $\mathrm{mgCH}_{4} / \mathrm{kg}$ và $0,280 \mathrm{mgCH}_{4} / \mathrm{kg}$, lần lượt giảm $21,83 \%$ và $49,64 \%$ so với đối chứng $(\mathrm{p}<0,05)$. Trong khi đó, tổng lượng $\mathrm{CH}_{4}$ của nghiệm thức bổ sung than tre $0,2 \%(\mathrm{BB} 2)$ và $0,5 \%(\mathrm{BB} 3)$ giảm lần lượt $42,53 \%$ và $27,47 \%$ so với đối chứng $(\mathrm{p}<0,05)$. Kết quả Hình 5 cũng cho thấy bổ sung than trấu ở mức $0,5 \%$ cho kết quả tốt nhất, khác biệt có ý nghĩa so với các nghiệm thức còn lại $(\mathrm{p}<0,05)$. Trong khi đó đối với than tre, nghiệm thức $0,2 \%$ cho hiệu quả tốt nhất, khác biệt so với nghiệm thức $0,1 \%$ và $0,5 \%$ $(\mathrm{p}<0,05)$.

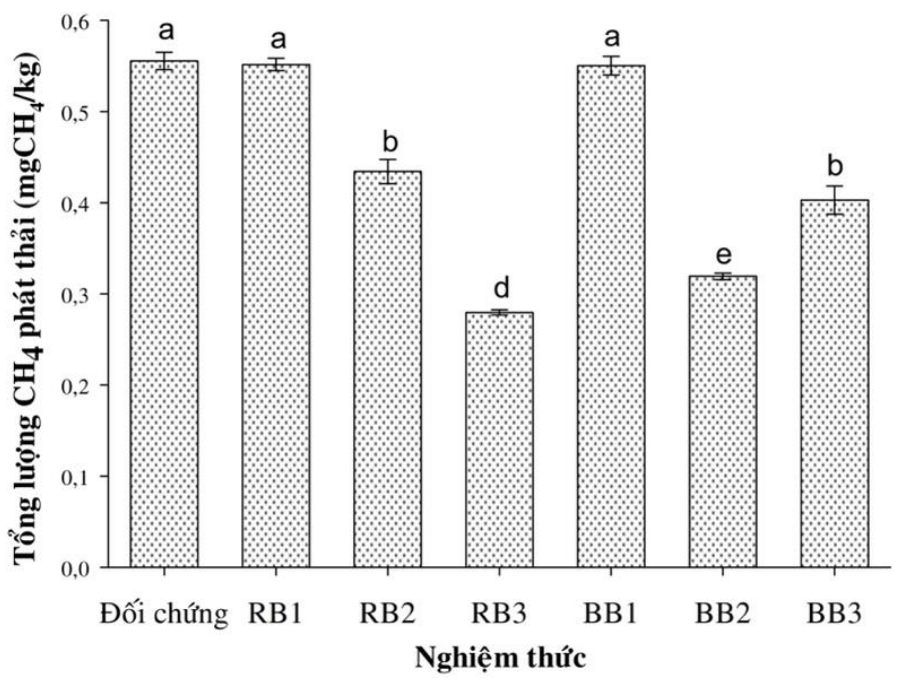

Hình 5: Tổng lượng phát thải $\mathrm{CH}_{4}$ trong thí nghiệm

Ghi chú: Các cột có cùng it nhất một chũ cái thì không khác biệt ở mức ý nghĩa thống kê 5\%; Đối chứng: nghiệm thức đối chúng, RB1: 0,1\% biochar trấu, RB2: 0,2\% biochar trấu, RB3: 0,5\% biochar trấu, BB1: 0,1\% biochar tre, BB2: $0,2 \%$ biochar tre và $B B 3: 0,5 \%$ biochar tre.

Bổ sung than sinh học trấu và tre làm giảm lượng $\mathrm{CH}_{4}$ phát thải trong đất có thể giải thích bằng cơ chế: (i) sự tác động biochar bổ sung $(\mathrm{pH}$ biochar 8,3-
9,37) làm $\mathrm{pH}$ trong môi trường ủ tăng cao làm ức chế sự phát triển của VSV sinh $\mathrm{CH}_{4}$ (Lehmann, 2007); (ii) vật liệu vỏ trấu và tre sau nhiệt phân thành 
biochar hình thành nhiều lỗ nhỏ, giúp tạo không gian trống giúp chứa và giữ lại oxy để VSV tiêu thụ $\mathrm{CH}_{4}$ methanotrophs phát triển trong giai đoạn háo khí ban đầu (Liu et al., 2011); (iii) ngoài ra biochar có nhiều lỗ rỗng có khả năng hấp phụ giữ lại $\mathrm{C}$, làm hạn chế sự phát thải lên khí quyền (Lehmann \& Joseph, 2009; Liu et al., 2011, Feng et al., 2012).

Hiệu quả bổ sung biochar được thể hiện qua các nghiên cứu trước đây của Rondon et al. (2005) và Lehmann (2007) cho thấy lượng khí thải $\mathrm{CH}_{4}$ đã được loại bỏ hoàn toàn bằng biochar (ở tầng mặt 1 $\mathrm{mm})$. Trong một thí nghiệm khác của Rondon et al. (2006) đã chứng minh sử dụng biochar từ gỗ bổ sung vào đất bạc màu ở vùng nhiệt đới đã làm giảm 200 $\mathrm{mgCH} / \mathrm{m}^{2}$. Nghiên cứu gần đây của Karhu et al. (2011) đã bổ sung 9 tấn biochar gỗ Bạch dương vào đất trồng lúa mì cho hiệu quả giảm phát thải $\mathrm{CH}_{4}$ đến $96 \%$ so với đất không bổ sung biochar. Kết quả nghiên cứu Liu et al. (2011) đã sử dụng 2 loại biochar rơm và tre bổ sung ở 3 tỷ lệ $0,5 \% ; 1,5 \%$ và $2 \%$ cho hiệu quả giảm phát thải $\mathrm{CH}_{4}$ rất tốt ở tỷ lệ $1,5 \%$ biochar tre giảm phát thải $51,1 \%$ và biochar rơm là $91,2 \%$. So sánh với các kết quả trước đó có thể thấy rằng hiệu quả giảm phát thải/tỷ lệ bổ sung than cao hơn từ 1,6 đến 2,49 lần. Với lượng biochar áp dụng nhỏ hơn từ 3 đến 12 lần so với các nghiên cứu đã thực hiện trước đó nhưng đã giúp cắt giảm lượng $\mathrm{CH}_{4}$ sinh ra từ đất trồng lúa từ $21,9-49,6 \% \mathrm{khi}$ bổ sung than trấu và $27,5-42,5 \%$ khi bổ sung than tre.

\section{KẾT LUẬN VÀ ĐỀ XUÂT}

Bổ sung than trấu hoặc than tre vào đất ngập nước với lượng từ 0,2 đến $0,5 \%$ có hiệu quả giảm phát thải $\mathrm{CH}_{4}$ từ 21,9 đến $49,6 \%$ và $27,5-42,5 \%$ tương ứng đối với than trấu và than tre. Than trấu bổ sung ở tỷ lệ $0,5 \%$ khối lượng đất làm giảm 49,6\% phát thải khí $\mathrm{CH}_{4}$ so với nghiệm thức đối chứng. Kết quả nghiên cứu cho thấy trong điều kiện thí nghiệm, đất ngập nước vẫn phát thải một lượng lớn $\mathrm{CH}_{4}$, kể cả không trồng lúa $(0,529-87,9 \mu \mathrm{gCH} / \mathrm{kg} / \mathrm{ngày})$. Các nghiên cứu tiếp theo cần được tiến hành thêm ở điều kiện ngoài đồng để đánh giá chính xác hơn hiệu quả giảm phát thải khí $\mathrm{CH}_{4}$ khi bổ sung than sinh học vào đất, vì trong điều kiện thực tế với các phương pháp cải tạo đất, quản lý nước, quản lý rơm rạ, phân bón sẽ là các nhân tố có thể ảnh hưởng đến mức độ phát thải $\mathrm{CH}_{4}$ cũng như tổng lượng phát thải.

\section{LỜI CẢM TẠ}

Đề tài này được tài trợ bởi Dự án Nâng cấp Trường Đại học Cần Thơ VN14-P6 bằng nguồn vốn vay ODA từ chính phủ Nhật Bản.

\section{TÀI LIẸU THAM KHẢO}

Barlett, K.B., Patrick, M.C, Daniel, I.S, Robert, C.H, John, O.W, \& John, M.M. (1988). Methane flux from the central Amazonian floodplain. Journal of Geophysical Research, 93(D2), 1571-1582.

Bộ Nông nghiệp và Phát triển nông thôn. (2017). Quyết định Công bố hiện trạng rừng toàn quốc năm 2016. https://www.mard.gov.vn/Pages/bo-nn-ptnt-congbo-hien-trang-rung-toan-quoc-nam-201633834.aspx.

Cheng, C.H., Lehman, J., \& Thies, J.E. (2016). Oxidation of black carbon by biotic and abiotic process. Journal Organic Geochemistry, 37(11), 1477-1488.

Chungsangusist, T., Gheewala, S. H., \& Patumsawad, S. (2009). Emission assessment of rice husk Combustion for power production. International Scholarly and Scientific Research and Innovation, 3(5), 625-630.

Conrad, R., Erkel, C., \& Liesack, W. (2006) Rice Cluster Imethanogens, an important group of Archaea producing greenhouse gas in soil. Current Opinion in Biotechnol, 17, 262-267.

Dubey, S.K. (2005). Microbial ecology of methane emission in rice agroecosysterm: a review. Journal Applied ecology and environmental research, 3(2), 1-27.

Feng, Y. Z., Xu, P., Yu, Y. C., Xie, Z. B., \& Lin, X. G. (2012). Mechanisms of biochar decreasing methane emission from Chinese paddy soils. Journal Soil Biology and Biochemistry, 46, 80-88.

Huỳnh Phan Khánh Bình \& Trương Thị Nga, 2018. Một số tính chất lý hóa của 3 loại than tràm, tre và trấu sản xuất bằng phương pháp truyền thống. Tạp chi Khoa hoc Đại hoc công nghệ nông nghiệp Truòng Đại học Nông Lâm, Đại học Huế, 2(3), 839-846.

Huỳnh Quang Tín, Trần Thị Huyền Trang, Võ Văn Bình, Trần Kim Tính \& Nguyễn Văn Sánh. (2015). Ảnh hưởng của kỹ thuật tới đến năng suất và phát thải methane $\left(\mathrm{CH}_{4}\right)$ trong sản xuất lúa tại Gò Công Tây - Tiền Giang. Tạp chi Khoa hoc Truòng đại học Cần Tho, Nông nghiệp, thủy sản và công nghẹ sinh hoc, 38(B), 55-63.

Inubushi, K., Umebyashi, M \& Wada, h. (1990). Methane emission from paddy fields. In: Transactions, $14^{\text {th }}$ international Congress of soil Scinece, Kyoto vol. 2, 249-254.

Karhu, K., Mattila, T., Bergstrom, I., \& Regina, K. (2011). Biochar addition to agricultural soil increased $\mathrm{CH}_{4}$ uptake and water holding capacity-results from a short-term pilot field study. Journal Agriculture Ecosystem and Environment, 140, 309-313. doi:10.1016/j.agee.2010.12.005 
Lehmann, J. \& Joseph. S. (2009). Biochar for Environmental Management: Science and Technology. London, UK: Earthscan Ltd: Free press.

Lehmann, J. (2007). A handful of carbon. Journal Nature, 447(7141), 143-144.

Liang, B., Lehmann, J., Solomon, D., Kinyangi, J., Grossman, J., O'neill, B., Skjemstad, J., Thies, J., Luizao, F. \& Petersen, J. (2006). Black carbon increases cation exchange capacity in soils. Journal Soil Science Society of America, 70(5), 1719-1730.

Liu, Y.M . Yang, Y,. Wu, H . Wang, Y. Chen, W., \& Wu. (2011). Reducing $\mathrm{CH}_{4}$ and $\mathrm{CO}_{2}$ emission from waterlogged paddy soil with biochar. Journal of Soils and Sediments, 11, 930-939. DOI 10.1007/s11368-011-0376-x

Mai Văn Trịnh, Trần Văn Thể \& Bùi Thị Phương Loan. (2013). Tiềm năng giảm thiểu phát thải khí nhà kính của ngành sản xuất lúa nước Việt Nam. Tạp chí Nông nghiệp và Phát triển Nông thôn $3 / 2013$.

MONRE. (2010). Viet Nam's second national communication to the United Nations Framework Convention on Climate Change. Ministry of Natural Resources and Environment (MONRE).

Ngô Ngọc Hưng. (2004). Giáo trình thực tập thổ nhương. Tủ sách đại học Cần Thơ.

Nguyễn Khoa Nam, Nguyễn Hữu Chiếm \& Nguyễn Văn Công. (2018). Sử dụng than tràm, than tre, than trấu và than hoạt tính gáo dừa làm giảm tác động của Fenobucarb đến enzyme cholinesterase được tách chiết từ các rô đồng (Anabas Testuduneus). Tap chi Khoa hoc Đại hoc Công nghệ Nông nghiệp Truờng Đại học Nông Lâm, Đại hoc Hué, 2(2), 733-740.

Nguyễn Văn Sinh. (2016). Anh hưởng của một số biochar khác nhau đến phát thải N2O trên đất vuờn cây ăn trái và đất phù sa trồng lúa. Báo cáo tổng kết đề tài nghiên cứu khoa học và công nghệ cấp trường (T2015-75). Trường Đại học Cần Tho.

Nguyen, X. L., Do, P. T., Nguyen H. C., Kose, R., Okyama, T., Pham N. T., Nguyen, D. P., \& Miyanishi, T. (2018). Properties of biochar prepared from local biomass in the Mekong delta, Vietnam. Journal Bioresources, 13(4), 7325-7344.

Parkin, T., Mosier, A., Smith, Venterea, J. R., Johnson, J., Reicosky, D., Doyle, G., McCarty, G., \& J. Baker. (2007). Chamber-based Trace Gas Flux Measurement Protocol. USDA-ARS GRACEnet. New York: Free press

Phạm Quang Hà, Vũ Thắng, Nguyễn Thị Khánh, Kimio Ito, Koichi Endoh \& Kazuyuki Inubushi. 2013. Đánh giá mức độ phát thải $\mathrm{CH}_{4}$ từ đất phù sa sông Hồng và đất xám bạc màu trồng lúa ở miền Bắc Việt Nam. Tạp chí Nông nghiệp và Phát triển nông thôn. Số tháng 3/2013.

Rondon, M. A., Molina, D., Hurtado, M., Ramirez, J., Lehmann, J., Major, J., \& Amezquita, E. (2006). Enhancing the productivity of crops and grasses while reducing greenhouse gas emissions through bio-char amendments to unfertile tropical soils. In: 18th World Congress of Soil Science, July 9-15, Philadelphia, PA. Retrieved June, 2008 from http://crops.confex.com/crops/wc2006/techprogra $\mathrm{m} / \mathrm{P} 16849 . \mathrm{html}$

Rondon, M., Ramirez, J. A,. \& Lehmann, J. (2005). Charcoal additions reduce net emissions of greenhouse gases to the atmosphere. In: Proceedings of the $3^{\text {rd }}$ USDA Symposium on Greenhouse Gases and Carbon Sequestration, Baltimore, USA, March 21-24,p208

Smith, P., Martino, D., Cai, Z., Gwary, D., Janzen, H., \& Kumar. (2007). Agriculture. In: Climate Change: Mitigation. Contribution of Working Group III to the Fourth Assessment Report of the Intergovernmental Panel on Climate Change, (pp. 497-540). Cambridge University Press, Cambridge, United Kingdom and New York: Free press.

Spokas, K.A., \& Reicosky, D.C. (2009). Impacts of sixteen different biochars on soil greenhouse gas production. Annals of Environmental Science, 3, 179-193.

Tô Lan Phương, Trần Minh Hải, Nguyễn Kim Chung \& Đặng Kiều Nhân. (2012). Ảnh hưởng của phân Biogro, phương pháp tưới tiết kiệm nước đến năng suất và phát thải khí nhà kính trên ruộng lúa. Tạp chí Khoa học Truờng Đại hoc Cần Tho, 22(a), 8-16.

Tổng cục thống kê. (2016). Niên giám thống kê 2016. https://www.gso.gov.vn/du-lieu-va-so-lieu-thongke/2019/10/nien-giam-thong-ke-2016-2/

Tổng cục thống kê. (2018). Niên giám thống kê 2018. https://www.gso.gov.vn/du-lieu-va-solieu-thong-ke/2019/10/nien-giam-thong-ke-2018/

Troy, M. S., Peadar, G., Lawlor, Cornelius. J, O’ Flynn., \& Mark G. H. (2013). Impact of biochar addtion to soil on greenhouse gas emissions following pig manure application. Jouranl Soil biology and biochemistry, 60, 173-181.

Võ Quang Minh \& Phan Thanh Vũ. (2015). Sử dụng có hiệu quả đất phèn, mặn ở Đồng bằng sông Cửu Long. Hội thảo quốc gia Đất Việt Nam Hiện trạng sử dụng và thách thức, 167-173

Wang, J. Y., Jia, J. X., Xiong, Z. Q., Khalil M. A. K., \& Xing, G. X. (2011). Water regime fertilizerstraw incorporation interaction: Field study on nitrous oxide emissions from a rice agroecosystem in Najing, China. Journal 
Agricultarure, Ecosystems and Environment, 141, 437-446.

Wang, N, Chang, Z. Z., Xue, X. M., Yu, J.G., Shi, X.X., \& Ma, L. Q. (2017). Biochar decreases nitrogen oxide and enhances methane emissions via altering microbial community composition of anaerobic paddy soil. Journal Science of Total Environment, 581-582, 689-696.

Weier K. L. (1999). $\mathrm{N}_{2} \mathrm{O}$ and $\mathrm{CH}_{4}$ emission and $\mathrm{CH}_{4}$ Consumption in sugarcane soil after variation in nitrogen and water application. Journal Soil biology and biochemistry, 31, 1931-1941.

Xiong, Z. Q., Xing, G. X., \& Zhu, Z. L. (2007). Nitrous oxide and methane emission as affected by water, soil and nitrogen. Journal Pedosphere, 17(2), 146-155.

Yoo, J., \& Kang, H. (2012). Effects of biochar addition on greenhouse gas emissions and microbial responses in a short-term laboratory experiment. Journal of Environmental Quality, Special section Environment benefits of biochar, 1193-1202.

Zwieten, V. L., Kimber, S., Morris, S., Downie, A., Berger, E., Rust, J., \& Scheer, C. (2010). Influence of biochars on flux of $\mathrm{N}_{2} \mathrm{O}$ and $\mathrm{CO}_{2}$ from Ferrosol. Journal Australian Journal of Soil Research, 48(6-7), 555-568. 